\title{
Characterizing Meteorological Scenarios Favorable for Septoria tritici Infections in Wheat and Estimation of Latent Periods
}

\author{
Matthias Henze, Marco Beyer, Holger Klink, and Joseph-Alexander Verreet, Institute of Phytopathology, Chris- \\ tian-Albrechts-University Kiel, Hermann-Rodewald-Strasse 9, D-24118 Kiel, Germany
}

\begin{abstract}
Henze, M., Beyer, M., Klink, H., and Verreet, J.-A. 2007. Characterizing meteorological scenarios favorable for Septoria tritici infections in wheat and estimation of latent periods. Plant Dis. 91:1445-1449.

Septoria tritici epidemics were monitored on winter wheat cv. Ritmo between 1995 and 2003 at 8 to 11 locations per year in Northern Germany (area between 53.70 and $54.38^{\circ} \mathrm{N}$ latitude and 8.83 and $10.88^{\circ} \mathrm{E}$ longitude) by counting the number of pycnidia on the leaves of plants obtained from plots under natural infection. Furthermore, meteorological data (leaf wetness, temperature, and precipitation) were recorded within the same period at the same locations. Groups of similar meteorological events were identified by hierarchical cluster analysis. The temporal distance of those clusters from the point of time when an increase of more than $70 \mathrm{~S}$. tritici pycnidia was observed per leaf within 1 week was calculated for all epidemiological case studies and meteorological clusters. A cluster with average temperature $=13.62 \pm 2.30^{\circ} \mathrm{C}$, leaf wetness $=92.39 \pm$ $4.15 \%$, and precipitation $=0.04 \pm 0.10 \mathrm{~mm}$ per day was consistently observed at $20.35 \pm 4.15$ days before epidemic outbreaks. This estimate of a latent period was significantly affected by geographic latitude, average temperature during infection, average temperature during the latent period, year, and precipitation, but not by leaf layer and longitude. On average, an increase in temperature during the infection period by $1{ }^{\circ} \mathrm{C}$ decreased latent periods by 0.95 day. Latent periods were decreased by 0.2 day upon an increase of the average temperature by $1^{\circ} \mathrm{C}$ during the latent period. Average latent periods decreased by 1.7 days per degree of north latitude. Latent period estimates had lower coefficients of variation than temperature sums accumulated over latent periods. The usefulness of the approach described above for general epidemiology and for increasing fungicide efficacy by improving the timing of applications is discussed.
\end{abstract}

Additional keywords: infection conditions, Mycosphaerella graminicola

Septoria tritici Desm. (teleomorph: $M y$ cosphaerella graminicola (Fuckel) J. Schröt.) is a fungal pathogen in cereals and the primary cause of leaf blotch on wheat worldwide $\quad(2,5,7,10,13,20,22)$. Yield losses caused by $S$. tritici were reported to range from 30 to $50 \%$ in the humid regions of Western Europe $(4,14)$.

Young winter wheat plants initially are infected by ascospores, often in autumn $(8,9,20)$, whereas the conidiospores are responsible for the epidemic spread and vertical transfer to the upper leaves in spring and summer $(8,14,16)$. The pathogen completes more than one life cycle each year and, therefore, causes a polycyclic plant disease $(14,24)$, which is more under the influence of weather conditions than a monocyclic disease. Potential control strategies include crop rotation, tillage, late seeding dates (18), growing resistant cultivars, and fungicide application. How-

Corresponding author: M. Beyer

E-mail: mbeyer@phytomed.uni-kiel.de

Accepted for publication 17 June 2007.

doi:10.1094/PDIS-91-11-1445

(c) 2007 The American Phytopathological Society ever, crop rotation and tillage were hardly effective as control methods (8) and late seeding contributes only marginally to the solution of the disease problem. Although growing resistant cultivars can be an effective approach to control the disease, currently grown cultivars do not have adequate resistance (15). Thus, fungicide applications dominate current control strategies. Fungicide efficacies greatly depend on the type of active ingredient and the timing of the application. With other fungal pathogens, the highest fungicide efficacies were observed when they were applied around the time of infection (6). Hence, focusing fungicide applications on infection events is desirable.

However, identifying the point of time of infection in the field can be a difficult task, because the sporulating structures such as pycnidia develop after a lag phase usually referred to as latent period. A direct approach to determine latent periods is to inoculate plants and monitor the development of pycnidia over time. Unfortunately, results of those experiments are biased by the permanent presence of a limited degree of natural background inoculum in diseases with a wide host range and aerial spore dispersal, such that it is questionable whether symptoms resulted from experi- mental inoculations (point of time known) or from natural inoculum (point of time unknown). An indirect approach would be the estimation of latent periods in growth chambers or greenhouses, where interfering effects of natural inoculum can be ruled out. Latent periods determined under controlled conditions could be used to estimate the point of time of infections by calculating back from the point of time where the first symptoms were observed in the field. Furthermore, environmental conditions favorable for infections may be identified by analyzing meteorological scenarios around the time of infections. This information would be useful for the development and improvement of forecast models. Unfortunately, latent periods of fungal pathogens determined in greenhouses or growth chambers may not be in agreement with field observations $(11,17)$. Earlier reports suggest that infections and subsequent disease development of $S$. tritici in wheat strongly depend on environmental factors such as leaf wetness and temperature $(11,16,19)$. Epidemic outbreaks (exponential multiplication of fungal structures such as pycnidia) are preceded by various meteorological scenarios.

The objectives of the present study were to (i) identify meteorological scenarios that precede epidemic outbreaks consistently, (ii) determine the temporal distance of those scenarios from the epidemic outbreak as an estimate of a latent period obtained from field data, and (iii) identify factors affecting latent periods.

\section{MATERIALS AND METHODS}

Plant material and data acquisition. Winter wheat (susceptible cv. Ritmo) was grown between 1995 and 2003 in 10- to $15-\mathrm{m}^{2}$ plots at 8 to 11 locations between the North and Baltic Sea (area between 53.70 and $54.38^{\circ} \mathrm{N}$ latitude and 8.83 and $10.88^{\circ} \mathrm{E}$ longitude). Wheat was sown using commercial multiple-row drills at 170 to 450 seed $\mathrm{m}^{-2}$ between 1 September and 25 October. Plots were plowed ( $83 \%$ of cases) or subjected to other tillage methods $(17 \%$ of cases) prior to sowing. Nitrogen fertilizers were applied at rates with $\mathrm{N}$ ranging from 130 to $280 \mathrm{~kg} \mathrm{ha}^{-1}$. No fungicides were applied. Ten main shoots were sampled in plots under natural infection at weekly intervals between plant growth stages 30 (start of stem elongation) and 85 (hard dough) (23). The upper four leaves were analyzed, because those leaves 
largely determine grain filling and infections greatly reduce yield $(1,21)$. The number of plots per location and year was $n=3$. The number of $S$. tritici pycnidia per leaf was counted under a stereoscope (model DRC; Zeiss, Oberkochen, Germany). A total of 86 location-year combinations, each with 10 plants per plot, three plots, four leaf layers, and 10 to 11 sampling dates, were used for data analysis.

Meteorological data (percent leaf wetness, temperature $\left[{ }^{\circ} \mathrm{C}\right] 20 \mathrm{~cm}$ above the ground, and precipitation $[\mathrm{mm}]$ ) were recorded hourly at all experimental locations using meteorological monitoring stations (model Weihofen; Adolf Thies GmbH \& Co. KG, Göttingen, Germany). The leaf wetness sensor measures electrical conductivity of a standardized piece of cotton wool. Leaf wetness is displayed on a relative scale, with the maximum conductivity of the completely water saturated wool = $100 \%$. The leaf wetness is a relative value for a point of time, but not the duration.

Data analyses. Meteorological data (hourly recordings, starting at 40 days before epidemic outbreaks) were subjected to a hierarchical cluster analysis using the CLARA (clustering large applications) option of the statistical software package $\mathrm{R}$ (R Foundation for Statistical Computing, Vienna, Austria; http://www.R-project.org) to identify groups (clusters) of similar meteorological events. Metric Euclidian distances were used as distance measure and the TRUE option was used for standardization of the meteorological vari- ables. The number of clusters was restricted to six because using more than six clusters did not make sense, due to the fact that additional clusters had only a few members. Based on a time scale, the distance of those clusters from the point of time when an increase of more than 70 pycnidia per leaf was observed within 1 week for the first time was calculated for all epidemiological case studies and clusters. The latter event subsequently is referred to as epidemic outbreak. Clusters characterized by (i) leaf wetness too low for $S$. tritici growth $(<80 \%)$ (5) or (ii) less than 100 cluster members were excluded from analysis. The temporal distance of the remaining clusters from the epidemic outbreak was used as an estimate of a latent period. Effects of temperature, location, year, precipitation, and leaf layer on the latent period were tested by analysis of variance, analysis of covariance, or linear regression using the software package SAS (Statistical Analysis System software package version 8.02; SAS Institute Inc., Cary, NC). Unless specified otherwise, data are presented as mean \pm standard error of the mean.

\section{RESULTS AND DISCUSSION}

Meteorological scenarios. Epidemic outbreaks (exponential multiplication of fungal structures such as pycnidia; Fig. 1A) were preceded by various meteorological scenarios (Fig. 1B). Hierarchical cluster analysis identified groups of meteorological events with high leaf wetness

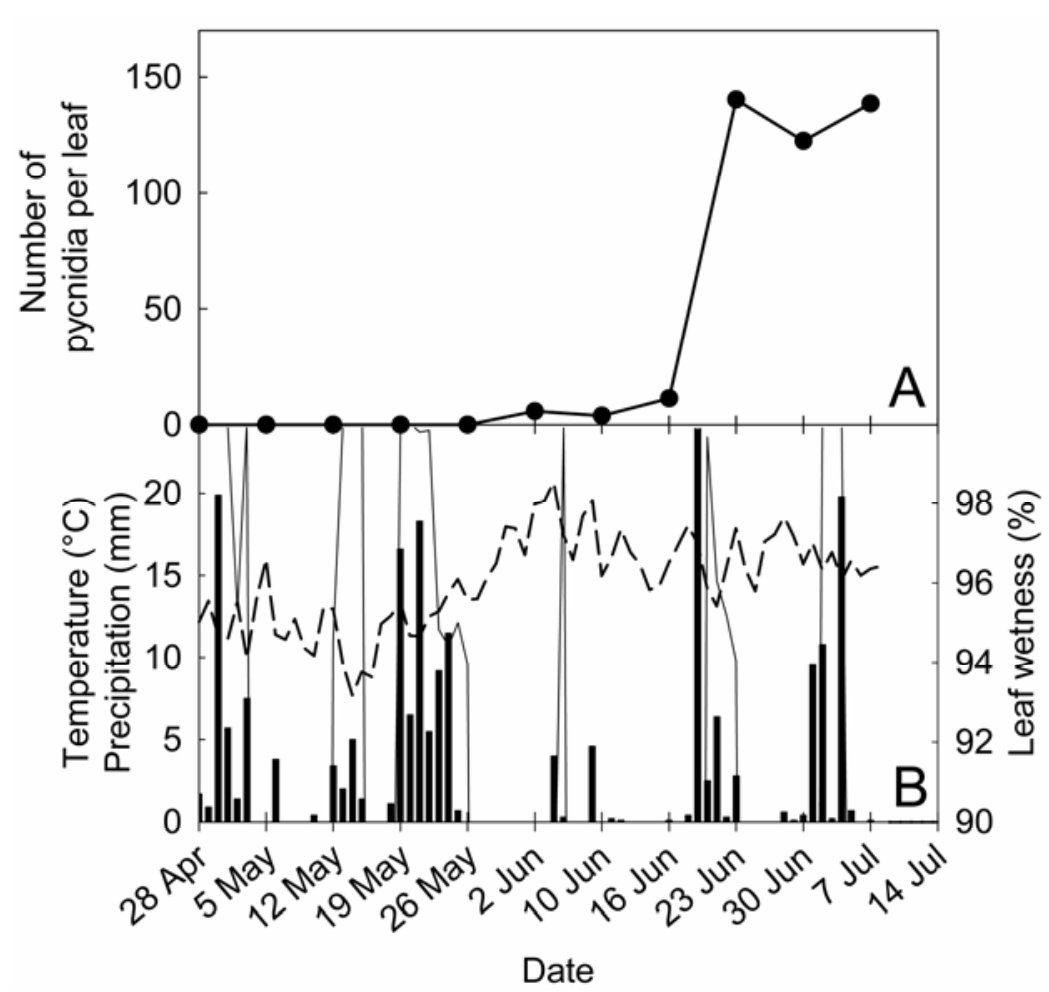

Fig. 1. A, Time course of the number of Septoria tritici pycnidia per wheat leaf (mean of 30 plants from three plots, leaf layer F-3). B, Temperature (dashed line), precipitation (black bar), and leaf wetness (solid line) at location Seestermühe in 2003.
(Fig. 2A; clusters 2, 4, and 5) and low leaf wetness (clusters 1, 3, and 6). Leaf wetness in the latter three clusters was too low to allow S. tritici infections (5). Hence, those meteorological scenarios probably were not related to $S$. tritici infections. Two out of three clusters (Fig. 2A; clusters 4 and 5) with high leaf wetness were very rare events, because hardly any cluster members were found in those groups (Fig. 2B). Those meteorological scenarios could account for a disease that occurs sporadically. However, S. tritici epidemics can be observed rather often in Northern Germany. Hence, cluster 2 seems to represent the most likely meteorological scenario for S. tritici infections. A similar cluster was observed in every data set with an epidemic outbreak and subsequently is referred to as infection cluster. The average temperature during the infection period was calculated from the data within the respective infection cluster and subsequently is referred to as average temperature during infection.

Factors affecting latent period estimates. The temporal distance of the infection clusters from the epidemic outbreak ranged from 10 to 32 days and averaged $20.35 \pm 4.15$ days (Fig. 3 ). The estimate of the latent period was significantly affected by geographic latitude $(P<0.001)$, average temperature during infection $(P<$
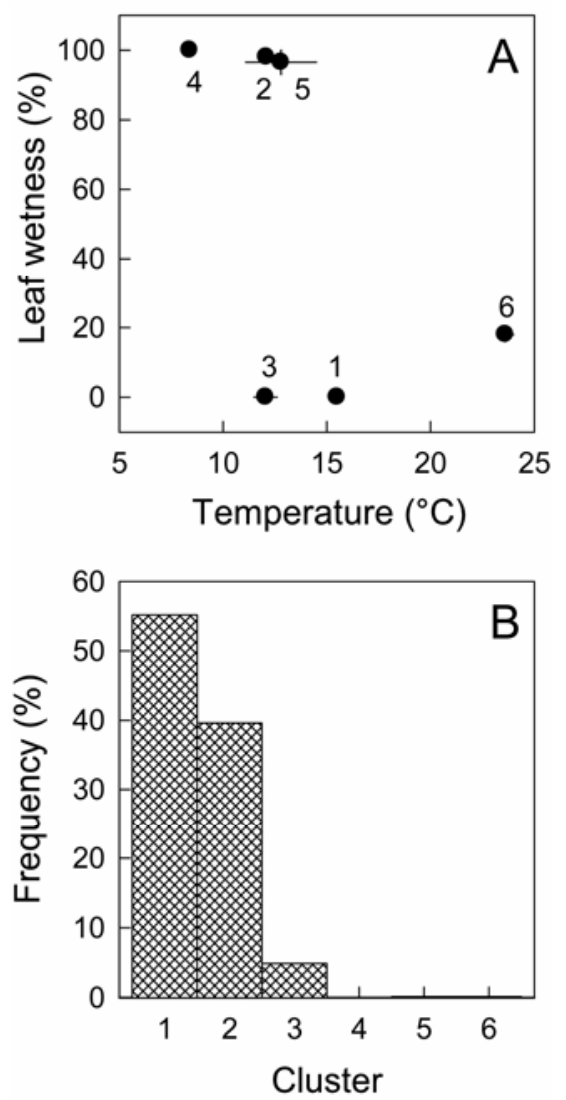

Fig. 2. A, Average leaf wetness and temperature of meteorological clusters. Numbers refer to the same clusters as depicted in $\mathbf{B}$, frequency distribution of cluster membership. 
0.001), average temperature during the latent period $(P<0.001)$, and year $(P<$ $0.001)$, and also slightly affected by precipitation $(P=0.033)$ (Table 1$)$. Effects of leaf wetness during infection, leaf layer, and longitude on the length of the latent period were insignificant at $P=0.650$, 0.519 , and 0.088 , respectively (Table 1 ). Average temperature, leaf wetness, and precipitation were $13.62 \pm 2.30^{\circ} \mathrm{C}, 92.39 \pm$ $4.15 \%$, and $0.04 \pm 0.10 \mathrm{~mm} \mathrm{day}^{-1}$ within the infection cluster, respectively.

Temperature. The effect of leaf layer was close to significance $(P=0.078)$ if the average temperature of the infection cluster was omitted as a covariate. It is evident that latent period estimates may differ among leaf layers because leaf layers were subjected to different temperatures during infection. F-3 leaves develop in spring, when the average temperature is lower than in summer, when flag leaves develop. Average temperatures during infections were $12.24 \pm 2.79^{\circ} \mathrm{C}$ for $\mathrm{F}-3$ leaves, 13.82 $\pm 2.74^{\circ} \mathrm{C}$ for $\mathrm{F}-2$ leaves, $14.12 \pm 2.4^{\circ} \mathrm{C}$ for $\mathrm{F}-1$ leaves, and $14.46 \pm 2.44^{\circ} \mathrm{C}$ for flagleaves (Fig. 4).

Regression parameters describing the relationship between the length of latent period and temperature during infection are given in Table 2 for each location and year. Case studies where less than three observations were available were excluded from analysis. However, some outliers were found in Table 2, in particular when few data points were available. To limit the impact of the outliers, medians of regression parameters were calculated instead of arithmetic means to estimate the overall relationship between average temperatures during infection and latent periods. On average, an increase in the average temperature during the infection period by $1{ }^{\circ} \mathrm{C}$ decreased latent period by 0.95 day (grand median line at the bottom of Table 2). An increase in the average temperature of $1^{\circ} \mathrm{C}$ during the latent period decreased it by on average 0.2 day. Magboul et al. (13) reported that successful infections were ob-

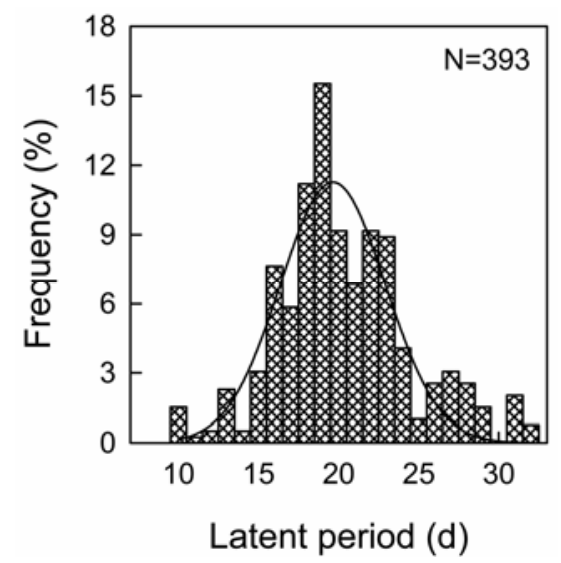

Fig. 3. Frequency distribution of latent period estimates. Cumulative data of all replicates, leaf layers, years, and sampling sites. tained within the temperature range of 16 to $19^{\circ} \mathrm{C}$ in an infection chamber when leaves were wet for $48 \mathrm{~h}$ or more. We observed epidemic outbreaks following temperatures during infection ranging from 6.58 to $22.59^{\circ} \mathrm{C}$ in the field. Infections in the first study (13) were caused by a single pycnidiospore isolate whereas infections in our field study were caused by many isolates. Different temperature optima of the isolates in our study may have caused the wider temperature range for infection.

Sampling sites and years. Latent periods differed between locations and years. Average latent periods decreased by 1.7 days per degree of north latitude and by 0.161 day per year. Even though statistically significant, the latter effect was not very consistent, in particular at those locations where epidemics occurred within the whole period of observation (Fig. 5). In 2000, latent periods were clearly longer (Fig. 5) and average temperature was lowest within the period of observation $\left(10.96^{\circ} \mathrm{C}\right.$ compared with the overall average of $13.62^{\circ} \mathrm{C}$ ). However, the impact of temperature alone cannot explain the variability in latent period estimates between years, because the effect of year also was observed when temperature was defined as a covariate in Table 1 . Hence, factors that were not recorded in the present study, such as variations in isolate aggressiveness, are likely to be responsible for the variability of latent periods among years.

Interestingly, latent periods decreased northward, suggesting that conditions were less suitable for the disease in the south of the region. Average temperatures decreased northward, but the effect was insignificant $(P=0.071)$. For a decrease of latent periods, an increase in temperature would be required (Table 2). Hence, the effect of latitude on latent periods was not a masked temperature effect. Factors that also change with latitude and that might become more suitable for a plant disease northward are increasing day length in summer or changes in the electromagnetic spectrum. However, further studies are needed either to support or to reject those hypotheses.

Timing fungicide applications. Fungicides are most effective when sprayed during infection. If meteorological scenarios suitable for $S$. tritici infections are recorded, fungicide applications may be recommended, for instance, by extension services. This basic approach was already implemented in the "Septoria Timer" (Adolf Thies $\mathrm{GmbH} \& \mathrm{Co} . \mathrm{KG}$ ), a device that displays a warning if leaf wetness periods exceed $48 \mathrm{~h}$. This simple approach already provided precious advice for timing and saving fungicide applications (4). The estimate of the latent period for $S$. tritici infections in wheat shall be used to (i) identify the period of time when infections occurred relative to epidemic outbreaks, (ii) revise critical leaf wetness duration for infection within this period, (iii) test whether critical leaf wetness duration for infection depends on other factors, and, if so, (iv) implement this more sophisticated knowledge into the Septoria Timer.

Critical evaluation of methods. An epidemic outbreak was defined as an increase of more than 70 pycnidia per leaf within 1 week. However, defining an epi-

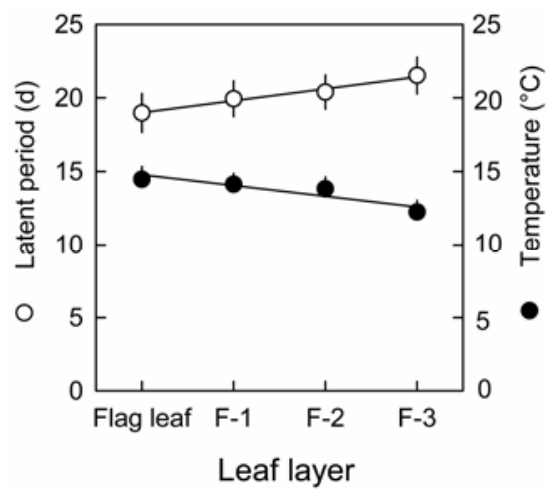

Fig. 4. Latent period estimates and average temperature during infection as related to leaf layer.

Table 1. Analysis of covariance for the effects of latitude ( ${ }^{\circ}$ North), longitude ( ${ }^{\circ}$ East), leaf wetness (\%), average temperature $\left({ }^{\circ} \mathrm{C}\right)$ during the infection period, precipitation $\left(\mathrm{mm} \mathrm{day}^{-1}\right)$ during the infection period, average temperature $\left({ }^{\circ} \mathrm{C}\right)$ during the latent period, leaf layers, and year on the latent period of Septoria tritici in wheat

\begin{tabular}{|c|c|c|c|c|c|c|}
\hline Parameters & Variable & $\begin{array}{c}\text { Sum of } \\
\text { squares }\end{array}$ & df & $\begin{array}{l}\text { Mean } \\
\text { square }\end{array}$ & $\boldsymbol{F}$ & $P$ \\
\hline \multirow[t]{6}{*}{ Covariates } & Latitude & 154.768 & 1 & 154.768 & 16.640 & $<0.001$ \\
\hline & Longitude & 27.129 & 1 & 27.129 & 2.917 & 0.088 \\
\hline & Leaf wetness ${ }^{a}$ & 1.915 & 1 & 1.915 & 0.206 & 0.650 \\
\hline & Temperature ${ }^{b}$ & 759.839 & 1 & 759.839 & 81.696 & $<0.001$ \\
\hline & Precipitation & 42.656 & 1 & 42.656 & 4.586 & 0.033 \\
\hline & Avg_t_lp ${ }^{c}$ & 154.569 & 1 & 154.569 & 16.619 & $<0.001$ \\
\hline \multirow[t]{2}{*}{ Main effects } & Leaf layer & 21.095 & 3 & 7.032 & 0.756 & 0.519 \\
\hline & Year & 993.060 & 8 & 124.133 & 13.346 & $<0.001$ \\
\hline Model & $\ldots$ & $3,276.334$ & 17 & 192.726 & 20.721 & $<0.001$ \\
\hline Residual & $\ldots$ & $3,487.818$ & 375 & 9.301 & $\ldots$ & $\ldots$ \\
\hline Total & $\ldots$ & $6,764.152$ & 392 & 17.255 & $\ldots$ & $\ldots$ \\
\hline
\end{tabular}

a Average leaf wetness during infection.

${ }^{\mathrm{b}}$ Average temperature during infection.

${ }^{c}$ Average temperature during latent period. 
Table 2. Regression parameters describing the relationship between latent period estimates and average temperature within the meteorological cluster during the time of infection ${ }^{\mathrm{a}}$

\begin{tabular}{|c|c|c|c|c|c|}
\hline Location & Year & $b$ (days) & $a\left(\operatorname{days}^{\circ} \mathrm{C}^{-1}\right)$ & $N$ & $R^{2}$ \\
\hline Eesch & 1998 & $32.51 \pm 2.83$ & $-1.04 \pm 0.19$ & 6 & 0.88 \\
\hline Eesch & 2000 & $34.84 \pm 4.16$ & $-0.95 \pm 0.35$ & 6 & 0.65 \\
\hline Eesch & 2002 & $33.82 \pm 7.24$ & $-1.15 \pm 0.51$ & 14 & 0.29 \\
\hline Eesch & 2003 & $20.91 \pm 0.00$ & $0.18 \pm 0.00$ & 6 & 1.00 \\
\hline Elskop & 2003 & $34.64 \pm 0.00$ & $-0.97 \pm 0.00$ & 8 & 1.00 \\
\hline Fegetasch & 1995 & $42.55 \pm 0.00$ & $-1.52 \pm 0.00$ & 6 & 1.00 \\
\hline Fegetasch & 1998 & $37.31 \pm 5.77$ & $-1.51 \pm 0.48$ & 6 & 0.71 \\
\hline Fegetasch & 2001 & $-34.32 \pm 34.22$ & $4.87 \pm 3.09$ & 3 & 0.71 \\
\hline Fegetasch & 2002 & $28.86 \pm 2.04$ & $-0.76 \pm 0.15$ & 23 & 0.56 \\
\hline Fegetasch & 2003 & $39.55 \pm 3.35$ & $-1.35 \pm 0.24$ & 9 & 0.82 \\
\hline Futterkamp & 1999 & $22.96 \pm 0.00$ & $-0.28 \pm 0.00$ & 4 & 1.00 \\
\hline Futterkamp & 2000 & $-188.65 \pm 83.76$ & $19.24 \pm 7.60$ & 5 & 0.68 \\
\hline Futterkamp & 2002 & $27.64 \pm 9.33$ & $-0.62 \pm 0.66$ & 11 & 0.09 \\
\hline Futterkamp & 2003 & $32.56 \pm 3.54$ & $-0.73 \pm 0.26$ & 10 & 0.50 \\
\hline Johannisdorf & 2002 & $48.01 \pm 2.50$ & $-2.03 \pm 0.18$ & 8 & 0.96 \\
\hline Kluvensiek & 1998 & $28.67 \pm 2.88$ & $-0.67 \pm 0.20$ & 13 & 0.50 \\
\hline Kluvensiek & 2000 & $32.69 \pm 2.59$ & $-0.93 \pm 0.24$ & 14 & 0.55 \\
\hline Kluvensiek & 2003 & $5.64 \pm 0.12$ & $1.23 \pm 0.01$ & 8 & 1.00 \\
\hline Louisenkoog & 1997 & $42.06 \pm 1.05$ & $-1.51 \pm 0.07$ & 3 & 1.00 \\
\hline Marienkoog & 2000 & $21.61 \pm 0.00$ & $0.00 \pm 0.00$ & 5 & 0.00 \\
\hline Marienkoog & 2002 & $47.03 \pm 7.46$ & $-2.15 \pm 0.50$ & 23 & 0.47 \\
\hline Marienkoog & 2003 & $73.45 \pm 0.00$ & $-3.69 \pm 0.00$ & 6 & 1.00 \\
\hline Niendorf & 1996 & $12.24 \pm 0.00$ & $0.62 \pm 0.00$ & 8 & 1.00 \\
\hline Niendorf & 1998 & $20.74 \pm 2.26$ & $-0.16 \pm 0.16$ & 21 & 0.05 \\
\hline Niendorf & 2001 & $52.69 \pm 11.04$ & $-2.06 \pm 0.83$ & 8 & 0.51 \\
\hline Niendorf & 2002 & $15.86 \pm 3.29$ & $0.22 \pm 0.22$ & 22 & 0.05 \\
\hline Niendorf & 2003 & $36.79 \pm 1.98$ & $-1.04 \pm 0.15$ & 10 & 0.85 \\
\hline Nienrade & 1996 & $37.27 \pm 5.60$ & $-1.12 \pm 0.45$ & 5 & 0.67 \\
\hline Nienrade & 1997 & $37.28 \pm 0.94$ & $-1.24 \pm 0.08$ & 4 & 0.99 \\
\hline Rabenholz & 2000 & $25.38 \pm 6.70$ & $0.03 \pm 0.68$ & 11 & 0.00 \\
\hline Ratzeburg & 2002 & $-360.12 \pm 0.00$ & $26.50 \pm 0.00$ & 4 & 1.00 \\
\hline Schönberg & 1995 & $64.85 \pm 0.00$ & $-3.13 \pm 0.00$ & 8 & 1.00 \\
\hline Schönberg & 1998 & $21.04 \pm 1.83$ & $-0.09 \pm 0.13$ & 17 & 0.03 \\
\hline Seestermühe & 1995 & $21.74 \pm 0.00$ & $0.00 \pm 0.00$ & 7 & 0.00 \\
\hline Seestermühe & 1997 & $35.76 \pm 1.18$ & $-0.97 \pm 0.09$ & 3 & 0.99 \\
\hline Seestermühe & 1998 & $46.05 \pm 14.00$ & $-2.03 \pm 1.10$ & 4 & 0.63 \\
\hline Seestermühe & 2000 & $55.04 \pm 2.90$ & $-2.73 \pm 0.24$ & 11 & 0.94 \\
\hline Seestermühe & 2002 & $25.47 \pm 1.94$ & $-0.49 \pm 0.13$ & 20 & 0.43 \\
\hline Sehestedt & 2002 & $45.68 \pm 2.89$ & $-1.89 \pm 0.22$ & 18 & 0.83 \\
\hline Overall regression & $\ldots$ & $31.13 \pm 0.89$ & $-0.79 \pm 0.07$ & 393 & 0.28 \\
\hline Grand median & $\ldots$ & $32.69 \pm 2.50$ & $-0.95 \pm 0.18$ & 393 & 0.71 \\
\hline
\end{tabular}

a Regression equations were $y=a x+b$, where $y=$ latent period (days), $a=$ change in latent period per unit temperature $\left(\right.$ days $\left.{ }^{\circ} \mathrm{C}^{-1}\right), x=$ temperature $\left({ }^{\circ} \mathrm{C}\right.$ ), and $b=$ intercept (days). Data sets with less than three observations were excluded from analysis; $N=$ number of data points and $R^{2}=$ coefficient of determination.

demic outbreak as an increase of 40 or 120 pycnidia per leaf within 1 week did not significantly affect latent period estimates $(P=0.41)$.

A rough estimate of the length of one disease cycle is a priori necessary, because no reasonable results will be obtained if the period of observation before an epidemic outbreak is too short to include the meteorological scenario that was, in fact, responsible for the infection. On the other hand, more and more meteorological events suitable for infection but not directly related to the particular epidemic outbreak under investigation will be included if this period is increased to an unrealistic extent. In the latter case, latent periods will be overestimated. Latent periods for $S$. tritici in wheat were reported to range from 11 to 42 days in previous studies $(3,11,19,22)$. Even though we used a new approach to estimate latent periods, our results are in general agreement with earlier reports. Latent periods $>40$ days were reported for temperatures $<4.3^{\circ} \mathrm{C}$ (19). Those low temperatures were not observed in our case studies with epidemic outbreaks.

As pointed out by Lovell et al. (12), most studies of plant pathology use physical time scales (hours or days), even when there is evidence to suggest that thermal time (temperature sums) may be a more appropriate measure. However, our latent period estimates had a lower coefficient of variation than temperature sums calculated over latent periods. Calculation of temperature sums requires a base temperature (12). No epidemic outbreaks were observed at temperatures $<6.58^{\circ} \mathrm{C}$ around the time of infection. Hence, this value was used as a provisional base temperature for calculating temperature sums. Coefficients of variation were $20 \%$ for latent period estimates and $23 \%$ for temperature sums (base temperature $=0^{\circ} \mathrm{C}$ ) or $29 \%$ (base temperature $=6.58^{\circ} \mathrm{C}$ ) during the latent period in our data set. Thus, it does not

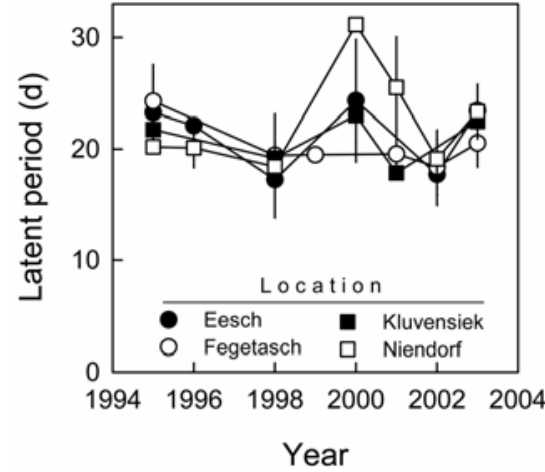

Fig. 5. Latent period estimates of Septoria tritici in wheat as affected by year and location.

seem to be advantageous to use temperature sums instead of latent periods in this case.

We developed an approach to estimate latent periods by identifying clusters of similar meteorological events with subsequent determination of the temporal distance of those clusters from the epidemic outbreak. A priori knowledge about the environmental factors that significantly affect infections is necessary to find suitable input variables for the cluster analyses and to exclude clusters that do not represent infection conditions. However, the present approach also may be useful in diseases or any other events that depend on scenarios that precede the event under investigation consistently. Hence, the approach introduced here can be expected to be valuable beyond the field of plant diseases; for instance, in general epidemiology or related scientific fields, where similar data structures and problems commonly occur.

\section{ACKNOWLEDGMENTS}

We thank C. Busse and I. Finger for technical assistance, H. Scherm (Univerity of Georgia) for critical comments on the manuscript, the staff of the Pflanzenschutzdienst des Landes SchleswigHolstein for providing plant samples, and the Stiftung Schleswig-Holsteinische Landschaft and the Deutsche Forschungsgemeinschaft for financial support.

\section{LITERATURE CITED}

1. Armour, T., Viljanen-Rollinson, S. L. H., Chng, S., Butler, R. C., Jamieson, P. D., and Zyskowski, R. F. 2004. Examining the latent period of Septoria tritici blotch in a field trial of winter wheat. N. Z. Plant Prot. 57:116120.

2. Bahat, A., Gelernter, I., Brown, M. B., and Eyal, Z. 1980. Factors affecting the vertical progression of Septoria tritici leaf blotch in short-statured wheats. Phytopathology 70:179184.

3. Brokenshire, T. 1976. The reaction of wheat genotypes to Septoria tritici. Ann. Appl. Biol. 82:415-423.

4. Burke, J., and Dunne, B. 2006. Septoria tritici in winter wheat-to spray or not to spray? Irish Farm. J. April 2006:14-18.

5. Chungu, C., Gilbert, J., and Townley-Smith, F. 2001. Septoria tritici blotch development as affected by temperature, duration of leaf wetness, inoculum concentration, and host. Plant Dis. 85:430-435. 
6. Cook, R. J., Hims, M. J., and Vaughan, T. B. 1999. Effects of fungicides spray timing on winter wheat disease control. Plant Pathol. 48:33-50.

7. Eyal, Z., Scharen, A. L., Huffman, M. D., and Prescott, J. M. 1985. Global insights into virulence frequencies of Mycosphaerella graminicola. Phytopathology 75:1456-1462.

8. Gladders, P., Paveley, N., Barrie, I., Hardwick, N., Hims, M., Langton, S., and Taylor, M. 2001. Agronomic and meteorologic factors affecting the severity of leaf blotch caused by Mycosphaerella graminicola in commercial wheat crops in England. Ann. Appl. Biol. 138:301-311.

9. Hunter, T., Coker, R. R., and Royle, D. J. 1999. The teleomorph stage, Mycosphaerella graminicola, in epidemics of Septoria tritici blotch on winter wheat in the UK. Plant Pathol. 48:51-57.

10. King, J. E., Cook, R. J., and Melville, S. C. 1983. A review of Septoria diseases of wheat and barley. Ann. Appl. Biol. 103:345-373.

11. Lovell, D. J., Hunter, T., Powers, S. J., Parker, S. R., and van der Bosch, F. 2004. Effect of temperature on latent period of Septoria leaf blotch on winter wheat under outdoor conditions. Plant Pathol. 53:170-181.
12. Lovell, D.J, Powers, S., Welham, S., and Parker, S. 2004. A perspective on the measurement of time in plant disease epidemiology. Plant Pathol. 53:705-712.

13. Magboul, A., Geng, S., Gilchrist, D., and Jackson, L. 1992. Environmental influence on the infection of wheat by Mycosphaerella graminicola. Phytopathology 82:1407-1413.

14. Palmer, C.-L., and Skinner, W. 2002. Mycosphaerella graminicola: latent infection, crop devastation and genomics. Mol. Plant Pathol. 3:63-70.

15. Pietravalle, S., Shaw, M., Parker, S., and van den Bosch, F. 2003. Modeling of relationships between weather and Septoria tritici epidemics on winter wheat: a critical report. Phytopathology 93:1329-1339.

16. Royle, D. J., Shaw, M. W., and Cook, R. J. 1986. Patterns of development of Septoria nodorum and $S$. tritici in some winter wheat crops in western Europe, 1981-83. Plant Pathol. 35:466-476.

17. Scherm, H., and van Bruggen, A. H. C. 1994. Effects of fluctuating temperatures on the latent period of lettuce downy mildew (Bremia lactucae). Phytopathology 84:853-859.

18. Shaw, M., and Royle, D. 1993. Factors determining the severity of Mycosphaerella graminicola (Septoria tritici) on winter wheat in the UK. Plant Pathol. 42:882-899.

19. Shaw, M. W. 1990. Effects of temperature, leaf wetness and cultivar on the latent period of Mycosphaerella graminicola on winter wheat. Plant Pathol. 39:255-268.

20. Shaw, M. W., and Royle, D. J. 1989. Airborne inoculum as a major source of Septoria tritici (Mycosphaerella graminicola) infections in winter wheat crops in the UK. Plant Pathol. 38:35-43.

21. Thomas, M. R., Cook, R. J., and King, J. E. 1989. Factors affecting development of Septoria tritici in winter wheat and its effect on yield. Plant Pathol. 38:246-257.

22. Verreet, J.-A., Hoffmann, G. M., and Klink, H. 2000. Regional monitoring for disease prediction and optimization of plant protection measures: the IPM wheat model. Plant Dis. 84:816-826.

23. Zadoks, C., Chang, T. T., and Konzak C. F., 1974. A decimal code for the growth stages of cereals. Weed Res. 14:415-421.

24. Zhan, J., Mundt, C. C., and McDonald, B. A. 1998. Measuring immigration and sexual reproduction in field populations of Mycosphaerella graminicola. Phytopathology 88:13301337 